\title{
Long-term morbidity and mortality after spinal cord injury: 50 years of follow-up
}

\author{
G Zeilig*,1, M Dolev ${ }^{1}, \mathrm{H}$ Weingarden ${ }^{1}, \mathrm{~N}^{*}$ Blumen $^{1}$, Y Shemesh $^{1}$ and A Ohry ${ }^{1}$ \\ ${ }^{1}$ Department of Neurological Rehabilitation, Sheba Medical Center, Tel-Hashomer, Israel
}

\begin{abstract}
Objective: To determine the long-term mortality rate and the types of morbidity among all people with spinal cord injuries (SCI) that occurred during the 1948 Israel War of Independence.

Method: Chart review and telephone interviews for collecting demographic data, injury characteristics, marital status, physical activities, employment, morbidity and mortality.

Results: Twenty individuals with SCI (19 males, one female). There was no regular follow-up during the first 20 years post injury. The most frequent morbidities were genito-urinary, cardiovascular and decubiti. Ten $(50 \%)$ had died during this overall follow-up interval. The average age at death was 60 years. The cause of death was cardiovascular in six, neoplastic disease in two, pneumonia in one, and one died from an unknown cause.

Conclusions: The data analysis showed that those who died participated less in physical activity and fewer were employed as compared to the survivors.

Spinal Cord (2000) 38, 563-566
\end{abstract}

Keywords: morbidity; mortality; spinal cord injury; long-term follow-up

\section{Introduction}

The morbidity rates for people with spinal cord injury (SCI) have considerably and gradually decreased during the past five decades. ${ }^{1}$ Consequently, the survival rates have improved. ${ }^{2}$ Modern emergency medical services, new medications and surgical procedures, antibiotics to combat infections and finally improved rehabilitation policies and services, have contributed to this progress.

In 1949, upon the invitation of the government of the new state of Israel, Sir Ludwig Guttmann, the father of modern SCI care, came to Israel and gave his expertise on the Israeli spinal cord patients injured during the 1948 War of Independence.

Since then we followed these individuals and their data were recorded. The main goal of our study was to determine the long-term survival rate and types of morbidity among the veterans who survived at least 1 year after sustaining a SCI.

\section{Patients and methods}

The Sheba Medical Center is a first level trauma center and includes a National SCI Rehabilitation Unit. Hospital records and follow-up charts were reviewed for all SCI patients from the Israel War of Independence (1948). All of them remained in our follow-up during the 50-year period. The only study

*Correspondence: G Zeilig, Department of Neurological Rehabilitation, Sheba Medical Center, Tel-Hashomer 52621, Israel criterion was 1-year post-injury survival. Twenty individuals with SCI met the inclusion criterion.

The data collected includes demographic and social information before and after the injury: age at injury, gender, marital status, employment status and regular physical activity. 'Regular' was defined as engaging in physical activity at least $6 \mathrm{~h}$ per week. Causes and severity of the spinal injury were recorded. The severity of the spinal injury was determined by the level of neurologic injury, the completeness of injury and by the American Spinal Injury Association (ASIA) impairment scale. ${ }^{3}$

The morbidity assessment was made from the registered data in the charts and by interviewing the participants. The dates and the causes of death were established by phone interview of the family and by medical certificates of death. The types of morbidity and the causes of death were analyzed according to the International Classification of Diseases: Ninth Edition (ICD9). ${ }^{4}$

\section{Results}

The results of the descriptive analyses are found in Table 1. There were nineteen males and one female. The mean age at injury was 22.6 years with a range of $17-36$ years. Most sustained the injury as a result of a gun shot wound (GSW). Other causes of injury were motor vehicle accidents and a fall from a height. The most common neurological deficit was paraplegia $\mathrm{T} 2-$ 
T9, ASIA A. There were no individuals with complete tetraplegia. Following the injury they remained hospitalized for an average of 3 years. There was no regular follow-up during the first 20 years post injury. At subsequent follow-up, $75 \%$ had married, $75 \%$ were employed and $45 \%$ were involved in regular physical activity. The most frequent morbidities were genitourinary, cardiovascular and pressure sores. Ten (50\%) died during this interval (Table 2). The average age at death was 60 years (range 55-65). Of those who died, the distribution of neurological deficits closely corresponded to the characteristics of the overall group. The main cause of death was cardiovascular in six cases: myocardial infarction and cardiac insufficiency in five, and a stroke in one. The other causes of death were cancer, pneumonia, and in one instance the cause of death remains unknown.

The main types of morbidity are found in Table 3 . There were no significant morbidity differences between the living and the deceased patients. However, physical activity and occupational status were significantly different between the two groups. Those belonging to the surviving group were more likely to have performed regular physical activity and to have been in regular employment at a rate of twoto-one compared to the deceased individuals (Table 4).

Table 1 Demographic characteristics

\begin{tabular}{lr}
\hline Variables & Numbers \\
\hline Gender & $19(95 \%)$ \\
Male & $1(5 \%)$ \\
Female & $22.6(17-35)$ \\
Age at injury & $15(75 \%)$ \\
Cause of injury & $4(40 \%)$ \\
Gun shot wound & $1(5 \%)$ \\
Motor vehicle accident & $13(65 \%)$ \\
Fall from height & $4(20 \%)$ \\
Neurologic deficit & $3(15 \%)$ \\
Paraplegia ASIA A & \\
Paraplegia ASIA C-D & \\
Tetraplegia ASIA C &
\end{tabular}

Table 2 Characteristics and causes of death

\begin{tabular}{lc}
\hline Variables & Numbers \\
\hline No. of deceased & $10(50 \%)$ \\
Age at death & $60(55-65)$ \\
Gender & Male $=10 ;$ Female $=0$ \\
Causes of death & $3(30 \%)$ \\
Ischemic heart disease & $2(20 \%)$ \\
Nonischemic heart disease & $2(20 \%)$ \\
Cancer & $1(10 \%)$ \\
Stroke & $1(10 \%)$ \\
Pneumonia & $1(10 \%)$ \\
Unknown & $6(60 \%)$ \\
Neurological deficit & $3(30 \%)$ \\
Paraplegia ASIA A & $1(10 \%)$ \\
Paraplegia ASIA C & \\
Tetraplegia ASIA C & \\
\hline
\end{tabular}

Table 3 Main types of morbidity

\begin{tabular}{lr}
\hline Morbidity & Numbers \\
\hline Urinary tract infections & $17(85 \%)$ \\
Pressure sores & $12(60 \%)$ \\
Genitourinary & $12(60 \%)$ \\
Cardiovascular & $11(55 \%)$ \\
Metabolic & $9(45 \%)$ \\
Musculoskeletal & $9(45 \%)$ \\
Gastrointestinal & $7(35 \%)$ \\
\hline
\end{tabular}

Table 4 Marital status, employment and physical activity numbers before and after the injury

\begin{tabular}{lccc}
\hline & & \multicolumn{2}{c}{ After } \\
Variables & Before & Living & Deceased \\
\hline Marital & $3(15 \%)$ & $9(90 \%)$ & $6(60 \%)$ \\
Employment & No data & $10(100 \%)$ & $5(50 \%)$ \\
Physical activity & No data & $6(60 \%)$ & $3(30 \%)$ \\
\hline
\end{tabular}

\section{Discussion}

The 20 people described in this study represent all the SCI population from the Israeli Independence War in 1948-1949. During the 50 years since, they had acute treatment, rehabilitation and the follow-up program done at the same medical facility. In the first 3 years after the injury they lived in the hospital in a special ward. In the period of time between their discharge until 1972 they had only sporadic spinal injury-oriented medical treatment and follow-up. Most of the medical care that they did receive was for the treatment of acute medical problems. In 1973 the National Spinal Cord Rehabilitation Unit was established and a regular follow-up program was initiated. This program was SCI oriented and thus focused on the specific problems related to the spinal cord injury, such as spasticity, pain, wound care and urinary management. In 1983 a multidisciplinary annual follow-up program was started, designed to manage both SCI related problems and other medical conditions, including secondary and tertiary prevention of chronic diseases. Compared to other studies, ${ }^{5-8}$ our data is unique since it describes a homogeneous group of people with a very similar social, medical and economic background, before and after the injury. In fact, at the time of injury, all were young soldiers, in good physical and medical condition. They all belonged to the lower economic class of new immigrants who had arrived in Israel at that time. After the injury, they were under the auspices of the veterans' administration, and as such they received ongoing social-economic support in addition to full coverage of all medical treatment.

British and American studies 5,7 have investigated large sample populations and have correlated between severity of injury, age at injury, gender, time and type of the first treatment, and mortality and morbidity rates and life expectancy. Heart diseases, respiratory, 
neoplastic conditions and infections were the most common underlying causes of death. Other studies ${ }^{9-12}$ have confirmed these findings.

Our study has several surprising and important findings, including the high percentage of individuals dying at a relatively young age and the significant differences in occupational status after the injury between the two groups. Other authors ${ }^{13,14}$ have described the completeness of the injury as affecting mortality, but the differences were not apparent in this relatively small cohort. In our study those who died participated less in physical activity. In the able-bodied population it is already known that a sedentary lifestyle and physical inactivity results in general deconditioning of the cardiovascular and other organ systems, and in a reduced work capacity. ${ }^{15}$ Many of the physiological alterations affecting the cardiovascular system have multiple factors, including diet, level of physical activity and chemical use. Furthermore, Erikssen $e t a l^{16}$ concluded in their study that change in physical fitness in healthy middle-aged men is a strong predictor of mortality and that even minor improvements in physical fitness are associated with a significantly lowered risk of death. Individuals with spinal cord injury, and especially those with complete injury who must adapt to a sedentary lifestyle because of the paralysis, may at an earlier age have the same adverse alterations in functions, which affect the cardiovascular system and lead to premature death. Lack of regular physical activity may increase this risk.

Another factor that may further explain the high rate of deaths, is the sex distribution of 19 males and only one female in this group. The data from the National Database shows that the male mortality rate is $27 \%$ higher than the female rate. In contrast to other studies ${ }^{6,17}$ none of our patients died as a result of septicemia or suicide. This is probably due to the high emphasis placed on patient education and routine long-term follow-up protocols for bladder and skin care. These individuals also had minimal economic or social difficulties.

The small group size, the years of injury (19481949), and the nearly uniform male gender of the patients, preclude using the data to predict the longterm survival of the SCI population. The data accumulated by the National Database ${ }^{5}$ shows that the mortality rate was reduced by $42 \%$ for persons injured between 1989 and 1992 relative to persons injured between 1973 and 1975 .

The people belonging to the living group had had regular employment almost twice as often as those who had deceased. This finding is consistent with Krause's results. ${ }^{18}$ Increased life satisfaction associated with employment was already described by Vogel et al in individuals who had pediatric spinal cord injury. ${ }^{19}$ Holicky et al stated that marital status was a significant predictor of better-perceived life satisfaction and quality of life among the SCI long-term survivor. ${ }^{20}$ Our data showed that more were married in the living group than in the deceased group. In fact, spouses may play an extremely important role in successful rehabilitation, long-term home care, and quality of life for people with SCI. Krause demonstrated that low overall quality of life is the most significant predictor of mortality among a cohort of more than 300 SCI people. ${ }^{18}$

In conclusion, this unique group of individuals formed a homogeneous cohort regarding socioeconomic background, community support and access to specialized SCI medical care. Analysis of the demographic data appears to confirm that high overall quality of life, combined with multidisciplined comprehensive rehabilitation, and long-term follow-up programs leads to maximizing longevity after SCI.

\section{References}

1 Menter RR. Issues of aging with spinal cord injury. In: Whiteneck GG, Charlifue SW, Gerhart KA, Lammertse DP, Manley S, Menter RR, Seedroff KR (eds). Aging with spinal cord injury. Demos publications: New York, NY, 1993, pp 1-8.

2 Ducker TB. Treatment of spinal cord injury. (Editorial). New Engl J Med 1990; 322: 1459-1461.

3 Ditunno JF, Young W, Donovan WH, Creasey G. The international standards booklet for neurological and functional classification of spinal cord injury. Paraplegia 1994; 32: 70-80.

4 Commission on Professional and Hospital Activities. The international classification diseases 9th revision clinical modification ICD-9-CM. Ann Arbor MI: Commission on Professional and Hospital Activities, 1978.

5 Frankel HL et al. Long-term survival in spinal cord injury: a fifty-year investigation. Spinal Cord 1998; 36: 266-274.

6 Hartkopp A et al. Survival and causes of death after traumatic spinal cord injury. A long-term epidemiological survey from Denmark. Spinal Cord 1997; 35: 76-85.

7 DeVivo MJ, Stover SL. Long-term survival and causes of death. In: Stover SL, DeLisa JA, Whiteneck GG (eds). Spinal cord injury: clinical outcomes from the Model systems. Aspen: Gaithersburg MD 1995, pp 289-316.

8 Whiteneck G et al. Mortality, morbidity and psychosocial outcomes of persons spinal cord injured more than 20 years ago. Paraplegia 1992; 30: 617-630.

9 Komura $\mathrm{T}$ et al. Characteristics of the health conditions of old patients with spinal cord injury. J. Hum Ergol 1994; 23: 151 - 157.

10 Yekutiel $\mathrm{M}$ et al. The prevalence of hypertension, ischaemic heart diseases and diabetes in traumatic cord injured patients and amputees. Paraplegia 1989; 27: $58-62$.

11 McColl MA et al. Expectations of life and health among spinal cord injured adults. Spinal Cord 1997; 35: 818-828.

12 Levi R, Hultling C, Seiger A. The Stockholm spinal cord injury study. 3. Health-related issues of the Swedish annual level-ofliving survey in SCI subjects and controls. Paraplegia 1995; 33: $726-730$

13 Samsa GP, Patrick CH, Feussner JR. Long-term survival of veterans with traumatic spinal cord injury. Arch Neurol 1993; 50: $909-914$

14 Yeo JD et al. Mortality following spinal cord injury. Spinal Cord 1998; 36: 329-336.

15 Ragnarsson KT, Moses LG. The cardiovascular system. In: Whiteneck GG, Charlifue SW, Gerhart KA, Lammertse DP, Manley S, Menter RR, Seedroff KR (eds). Aging with spinal cord injury. Demos publications: New York, NY, 1993, pp 73-92.

16 Erikssen $\mathrm{G}$ et al. Changes in physical fitness and changes in mortality. Lancet 1998; 352: 759-762.

17 Rish et al. Spinal cord injury: a 25-year morbidity and mortality. Mil Med 1997; 162: 141-148. 
18 Krause JS. Mortality after spinal cord injury: an 11-year prospective study. Arch Phys Med Rehabil 1997; 78: 815-821.

19 Vogel LC et al. Long-term outcomes and life satisfaction of adults who had pediatric spinal cord injuries. Arch Phys Med Rehabil 1998; 79: 1496-1503.
20 Holicky R, Charlifue S. Ageing with spinal cord injury: the impact of spousal support. Disabil Rehabil 1999; 21: 250-257. 